\title{
Technical Approach for Second Language Acquisition (SLA) Testing Using Multimodal Environments
}

\author{
PhD. Teresa Magal-Royo \& PhD. Jesús García-Laborda
}

\begin{abstract}
Communication is an everyday interaction which allow to express feelings, actions and situations between us. These are very important tasks for the second acquisition language in students.

The multimodality perception in learning and also in learning resources is necessary to acquire a new idiom because the communication has different levels, always mixing together. It is very difficult to learn a new language reading texts only e.g. In fact it is used several types of learning strategies mixing different types of communication (listen, reading, oral conversations, tec..) which improve de skills related to knowledge of a new language.

The new technical process and devices using in educational multimodal environments will be able to discover new educational interfaces oriented to facilitate the communications between the users and the devices as a new framework scenario to improve the ways of learn in the future.

In second language acquisition, SLA for Language Learners, ELLs the skills assessment would be improved if learning and testing digital platforms consider in their design the multimodal technical approach in the user interface.

This paper describe the use of multimodal technical interfaces applied to testing in a second language. It could be useful to complement the multimodal process of language learning and the assessment test interface.
\end{abstract}

Keywords - Second Language Acquisition (SLA), testing, multimodal interfaces, multimodal learning.

\section{INTRODUCTION}

$\mathrm{M}_{\mathrm{r}}$ ULTIMODAL systems in computer interface is directly related to the behavior of the human communication in the society. In human interfaces the connexion between different cognitive processes (view, listening, writing, etc...) during the acting of learn is the most important thing to be implement a new user interface adapted to a specific task.

The technological advances in programming languages on computers and mobile devices are allowing to develop multimodal communication scenarios combined for input and output data intended to improve the learning experience of the

PhD.Teresa Magal-Royo. Engineering Graphic Department., Universitat Politécnica de Valencia, 46022 Valencia, Spain, (phone:+34 666824192; e-mail: tmagal@ degi.upv.es).

PhD. Jesus Garcia Laborda. Modern Philology Department, Universidad Alcalá de Henares, 28801 Alcalá de Henares - Madrid, Spain. (phone:+ 3491 885 5041; e-mail: jesus.garcialaborda@uah.es) user for any learning task. The most basic multimodal input data systems interface combine the mouse and keyboard for instance other advanced multimodal systems combine up to three types of interactions; touch, pencil, speech recognition. In any case it is need it a study of efficiency for specific task to be developed.

The advantages of multimodal environments can improve the experience of communication between user and machine and are better accepted by the user. In fact it has been shown that for certain tasks relating to multimodal learning some environments are more efficient than others. For example with $3 \mathrm{D}$ objects task on a computer multimodal combination of speech recognition and gestures it is the best (Hauptmann, 1989) while the combination of keyboard-based graphical interface and touchpad is the best for writing text and linguistic task related (Oviatt et Al., 1994), (Oviatt, 2013)

Most of the virtual learning interface oriented to second language acquisition, SLA using this traditional input combined with mouse when the user has to develop a specific task like answer questions, creating a redaction, or do a test in a computer o ubiquitous device and a few experiences take in account the benefits using a multimodal interface for it, (Magal-Royo \& Gimenez-Lopez, 2012).

The learning scenarios using multimodal interface as well as multimodal learning experience in the classroom has benefits for the students learnability in any situation, (Jewitt \& Cowan, 2014), and in many cases it is necessary an adaptation and technical implementation depending of the specific task has to perform by the learner.

In SLA the testing scenario needs to be rethinking from the real needs of the learner to develop an effective multimodal interface using the hardware and software oriented to ubiquitous devices (Magal-Royo et Al., 2012).

The potentiality using smartphones and tablets devices as an educational support for testing and assessment of language's skills could be consider to improve b-learning and m-learning methodologies in the current educational environment.

\section{USER'S INTERACTION WITH MULTIMODAL TECHNIQUES}

In Multimodal User Interfaces MUIs are involved at group of two or more combined user input modalities (e.g. speech, pen, touch, gesture, head and body movements, etc...) in a coordinated manner with output modalities. An input modality 
the user generated an information is captured by input devices (e.g. speech, pen) or sensors. An output modality corresponds to a stimulus to human senses (hearing, smell, touch, taste, or vision) using audiovisual devices (e.g. tactile feedback).

Input modalities use human actions (e.g. speech, gestures) recognizers are capable of identifying input modalities captured by an input device or sensor. For example, an ASR (Audio Speech Recognition) recognizer identifies sentences in audio samples captured by a microphone. In multimodality is necessary to fusion several input modalities to interpret user intentions and the interpretation should consider contextual information; for instance, it should not expect voice commands from a speech-impaired user or when the user is in a loud place. (Guedes et Al., 2016).

This is very important in multimodal learning systems because It is necessary a feedback from the system inputs and outputs data. The output modalities recover the stimuli perceived by the human senses (e.g. hearing, vision) and producing output modalities through audiovisual devices, (e.g. a Text-To-Speech TTS synthesizer produces audio to be played by a speaker)

The choice of which modalities are used in the message is called modality selection, which must also consider contextual information in learner's environments. Context management is responsible for tracking and storing the contextual information in educational environments for instance..

\section{ASSESSMENT PROCESS IN SLA}

The assessment process need to define the skills will be able to analyzed and evaluate. In general, Canale and Swain define four components of communicative competences as the ability to use grammatical, sociolinguistic, discourse and strategic skills, (Canale \& Swain, 1980), (McLaughlin, 1987). Anderson stablish three stages of skill acquisition (cognitive, associative, and autonomous) have important implications both for understanding the process of second language acquisition and for developing instructional approaches. At least four issues in second language acquisition can be examined through the theory of cognitive skills acquisition: (1) the parallel between stages and second language constructs; (2) the learner's awareness of learning processes; (3) the rate of language acquisition for selected learning tasks; and (4) the retention or loss of language over time, (Anderson's, 1982).

The learning strategies related to teaching English as a foreign language was stablish by O'Malley and Chamot in the $90, \mathrm{~s}$ as a direct communication between the learners and the teacher in a physical collaboration. This strategies are used around the word and it is the basement of the educational planning in all levels of learning an idiom as a second language (O'Malley \& Chamot, 1990:179) (See table I).
TABLE I

FOREIGN LANGUAGE COMMON STRATEGIES TASKS

\begin{tabular}{|c|c|c|c|}
\hline Task & Description & Strategies & How to used \\
\hline $\begin{array}{l}\text { Listening } \\
\text { comprehe } \\
\text { nsion }\end{array}$ & $\begin{array}{l}\text { Student } \\
\text { listened to the } \\
\text { audio of } \\
\text { authentic } \\
\text { dialogues } \\
\text { between } \\
\text { persons in } \\
\text { common } \\
\text { situations. }\end{array}$ & $\begin{array}{l}\text { - Selective } \\
\text { attention. } \\
\text { - Inferencing. } \\
\text { - Elaboration. } \\
\text { - Transfer. }\end{array}$ & $\begin{array}{l}\text { - Focus on specific } \\
\text { items while listening. } \\
\text { - Use what you know. } \\
\text { - Make logical guesses. } \\
\text { - Recognize } \\
\text { communicational } \\
\text { patterns. }\end{array}$ \\
\hline $\begin{array}{l}\text { Reading } \\
\text { comprehe } \\
\text { nsion }\end{array}$ & $\begin{array}{l}\text { Students } \\
\text { identified } \\
\text { reading } \\
\text { strategies, } \\
\text { paragraph } \\
\text { structures and } \\
\text { new words }\end{array}$ & $\begin{array}{l}\text { - Inferencing. } \\
\text { - Deduction. } \\
\text { - Elaboration. } \\
\text { - Transfer. }\end{array}$ & $\begin{array}{l}\text { - Use prior knowledge } \\
\text { - Recognize structures } \\
\text { and patterns. } \\
\text { - Use immediate context } \\
\text { to guess new words } \\
\text { - Use grammar rules to } \\
\text { identify words. }\end{array}$ \\
\hline Speaking & $\begin{array}{l}\text { Students } \\
\text { worked in } \\
\text { groups or } \\
\text { peers to } \\
\text { prepare a } \\
\text { section of } \\
\text { difficult } \\
\text { reading text } \\
\text { to understand } \\
\text { it. }\end{array}$ & $\begin{array}{l}\text { - Cooperatio } \\
\mathrm{n} . \\
\text { - Social } \\
\text { Communic } \\
\text { ation. } \\
\text { - Self- } \\
\text { evaluation }\end{array}$ & $\begin{array}{l}\text { - Use synonyms, } \\
\text { phrases, gestures, } \\
\text { etc...to communicate } \\
\text { meanings } \\
\text { - Work in pair or } \\
\text { groups to plan and/or } \\
\text { evaluate the task } \\
\text { - Check the ability to } \\
\text { communicate } \\
\text { successfully }\end{array}$ \\
\hline Writing & $\begin{array}{l}\text { Students has } \\
\text { to write a } \\
\text { redaction } \\
\text { using spelling } \\
\text { skills, syntax } \\
\text { rules }\end{array}$ & $\begin{array}{l}\text { - Inferencing. } \\
\text { - Deduction. } \\
\text { - Elaboration. } \\
\text { - Transfer. }\end{array}$ & $\begin{array}{l}\text { - Use grammar. } \\
\text { - Spelling Rules. } \\
\text { - Syntax rules } \\
\text { - Use words, phrases } \\
\text { with a grammar } \\
\text { structure related to a } \\
\text { test o title proposition }\end{array}$ \\
\hline
\end{tabular}

Extracted and adapted from (O'Malley \& Chamot, 1990).

The evaluation functions are set forth as for determine Learning outcomes and quality of these, provide Information to guidance and regulation of the teaching-learning process and serve Track teaching and learning, that is, seen as a means or resource for the training of students.

In general, to evaluate student progress as English Language Learning (ELLs) take in account the development of skills in different levels. As an example, the ELL Standards Committee for the Ministry of Education in British Columbia (British Columbia, 2001) classifies the evaluation in three types:

- Initial evaluation. It is characterized by providing information about the ability possessed by the student about listening comprehension (initial diagnosis).

- Summative evaluation. It is characterized by running at the end of the process, through which a balance of what the student has learned (final diagnosis) is established.

- Formative assessment. It is characterized by providing information about the development of the process itself and allows us to intervene to adjust, gradually if necessary, the process of listening and better results.

\section{MUlTIMODAL TECHNIQUES IN SLA DIGITAL SCENARIOS}

The multimodal techniques applied to educational interfaces 
are oriented to the use and management of information through recognition of multiple communication channels depending on the device used. However, the concept of multimodal techniques in education is also related to those processes by using artificial intelligence, IA that allow students to learn different processes, strategies and sources combined with computer systems, (Luckin et al, 2016) (Price \& Jewitt, 2013).

There are several online computer-based applications for foreign language learners. These platforms allow the creation of customized training itineraries that students can follow to acquire a language. They also offer the possibility of design and use specific tests that allow the learners monitoring his progress periodically through the revision of their speaking, writing, listening and speaking performance at different competence levels.

Virtual classroom synchronized integration in multimodal scenarios is the key for use in effective learning environments. Integration needs of computer languages that are currently being developed to be implemented for applications via internet and ubiquitous devices (Dahl, 2013) and by standards recognized by programming developers (W3C, 2012).

For language learning, various research oriented Computer Assisted Language Learning, CALL have been developed over the last 10 years in various national projects in Spain like the case of OPENPAU project, demonstrated the effectiveness in the use and accessibility of multimodal techniques in developing proficiency tests in computer assisted English language (Garcia-Laborda et. al, 2010), (Garcia-Laborda et al., 2014).

Developed the research experiences mentioned above, allow to assess and control the impact on language learners LLEs in languages certification test like the English as a Foreign Language Internet-Based Test TOEFL iBT $^{\mathrm{TM}}$ and IELTS ${ }^{\mathrm{TM}}$, the Cambridge Board of Examinations suite (Cambridge First, Cambridge Advanced, PET ${ }^{\mathrm{TM}}$ and their versions for schools) will be able to define new creation processes for multimodal environments in SLA (See Figure 1). The possible issues to consider in the future are:

- User's selection the type access multimodal to the test. This is important to improve accessibility to the learning environment and facilitate data entry depending on user's cognitive abilities.

- Data verification issued during the validation and the information provided before and after by the user.

- Create multi-modal tests allow qualitative and quantitative analysis data for evaluate the knowledge and/ or skills acquired by the student during learning a language.

- Improve learning resources through combined multimodal techniques that approximate real learning with learning tailored to a student's abilities.

- To improve multimodal synchronous communication channels in ubiquitous educational platform for long life learning.

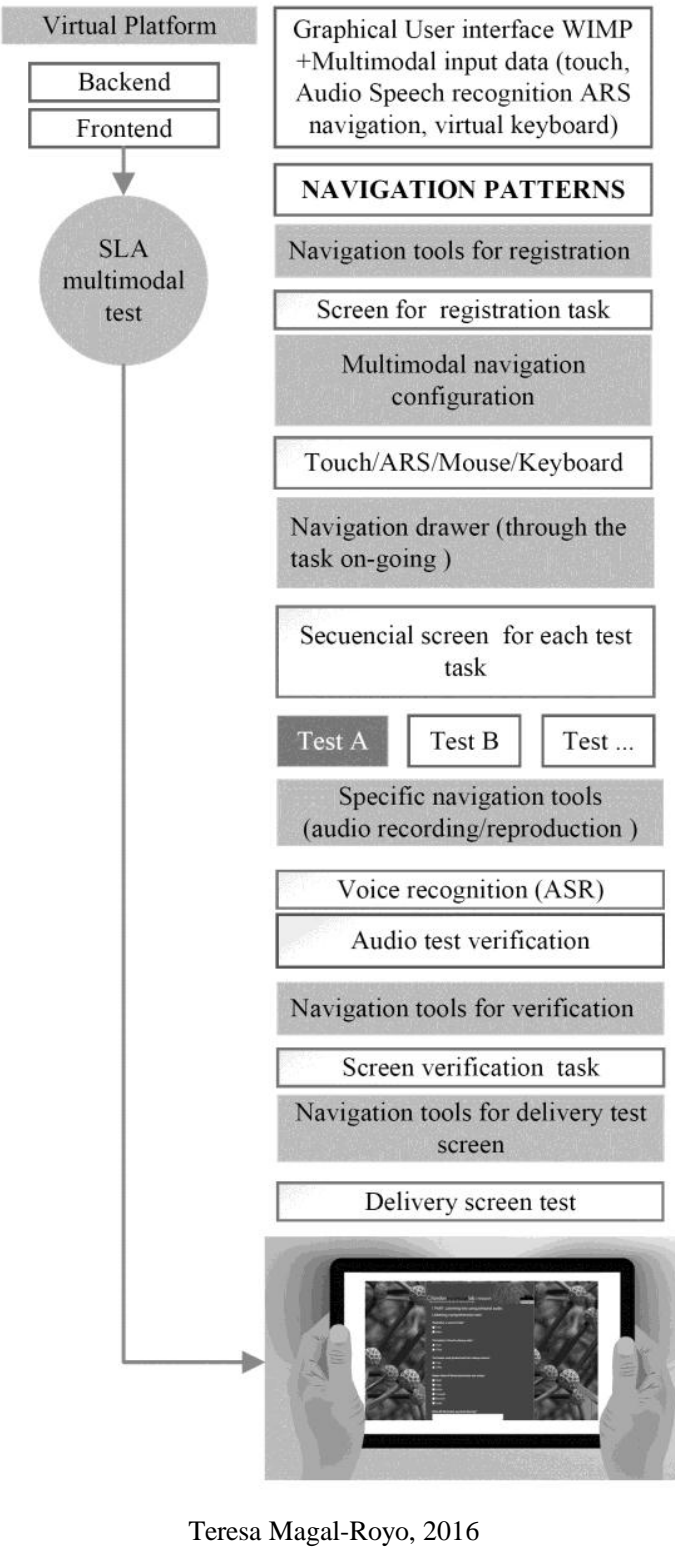

Fig 1: Multimodal SLA scenario navigation patterns

\section{V.CONCLUSIONS}

The design, creation and development of multimodal environments for language learning SLA can create multiple benefits in today's learning strategies as possible in future to create more and more accessible to the user more functional and real environments. Improving technology-oriented to Artificial Intelligence, IA new devices and new protocols adapted to multimodality in Internet applications will be key to the adaptation of new learning styles to long life learners.

\section{ACKNOWLEDGMENT}

The author would like to express their gratitude to the Spanish Ministry of Education, Culture and Sports for providing the grant, Senior Researchers Mobility project: Evaluate the multimodal interaction for Second Language Acquisition SLA testing in smartphones devices 
(PRX16/00171), for develop the present article. And also thanks to London Knowledge Lab from University College London for support the research project.

\section{REFERENCES}

[1] Anderson J.R. (1982). Acquisition of cognitive skills. Psychological Review Vol.89, pp. 369-406. https://doi.org/10.1037/0033-295X.89.4.369

[2] British Columbia, (2011). ELL Standards Committee report. Ministry of Education. British Columbia, https://goo.gl/H23q8x (Consulted 30/10/2016)

[3] Canale, M., and Swain, M. 1980. Theoretical bases of communicative approaches to second language teaching and testing. Applied Linguistics Vol. 1, pp.1-47. https://doi.org/10.1093/applin/1.1.1

[4] Dahl D.L. (2013) The W3C multimodal architecture and interfaces standard. Journal on Multimodal User Interfaces 7 (3), 171-182 https://doi.org/10.1007/s12193-013-0120-5

[5] García Laborda, J., Magal Royo, T., da Rocha Siqueira, J. M. y Fernández Álvarez, M. (2010). Ergonomics factors in English as a foreign language testing: The case of PLEVALEX. Computers \& Education Vol. 54 (2), 384-391. https://doi.org/10.1016/j.compedu.2009.08.021

[6] García Laborda, J., Magal Royo, T., Litzler, M.F. \& Giménez López, J.L. (2014). "Mobile phones for a University Entrance Examination language test in Spain". Educational Technology \& Society, 17(2), 1730.

[7] Guedes, Á.L.V., Azevedo, R.G.d.A. \& Barbosa, S.D.J. (2016) Extending multimedia languages to support multimodal user interactions. Multimedia Tools and Applications. doi:10.1007/s11042016-3846-8

https://doi.org/10.1007/s11042-016-3846-8

[8] Hauptmann, A.G. (1989). Speech and Gestures for graphic image manipulation. Proceedings of the Conference on Human factors in computer systems (CHI,89) ACM Press, New York Vol. 1 pp. 241-245 https://doi.org/10.1145/67449.67496

[9] Jewitt, C., \& Cowan, K. (2014). Special issue: 'Multimodality, discourse and learning'. Classroom Discourse, 1 (5). doi:10.1080/19463014.2013.859847 https://doi.org/10.1080/19463014.2013.859847

[10] Magal-Royo T., Gimenez-López J.L. and García Laborda J. (2012) Multimodal Interaction on English Testing Academic Assessment. Procedia - Social and Behavioral Sciences Vol. 46, pp. 5824 - 5827. doi:10.1016/j.sbspro.2012.06.522 https://doi.org/10.1016/j.sbspro.2012.06.522

[11] Magal-Royo, T., Gimenez López. J.L. (2012). Multimodal Interactivity in the Foreign Language Section of the Spanish University Admission Examination. Revista de Educacion Vol.357 pp.163-176.

[12] McLaughlin B. (1987). Theories of second-language learning. London: Edward Arnold.

[13] Luckin, R., Holmes, W., Griffiths, M., and Forcier, L. B. (2016). Intelligence Unleashed. An argument for AI in Education. Pearson.

[14] O'Malley, J. M. and Chamot A. U. (1990). Learning Strategies in Second Language Acquisition. Cambridge: Cambridge University Press. https://doi.org/10.1017/CBO9781139524490

[15] O'Malley, J. M., Chamot, A. U., and Küpper, L. (1989). Listening comprehension strategies in second language acquisition. Applied Linguistics Vol 10(4) pp. 418-437

https://doi.org/10.1093/applin/10.4.418

[16] Oviatt S.L (2013). The Design of Future Educational Interfaces. Routledge. New York, USA ISBN 978-0415894944

[17] Oviatt S.L., Cohen P.R., Wang M. (1994). Toward interface design for human language technology - Modality and structure as determinants of linguistic complexity. Speech Communication, Vol. 15 (3-4), pp.283300. doi: 10.1016/0167-6393(94)90079-5 https://doi.org/10.1016/0167-6393(94)90079-5

[18] Price, S., \& Jewitt, C. (2013). A multimodal approach to examining 'embodiment' in tangible learning environments. ACM SIGCHI. https://doi.org/10.1145/2460625.2460632
[19] WW3C (2012) Recommendation. $30 / 10 / 2016)$

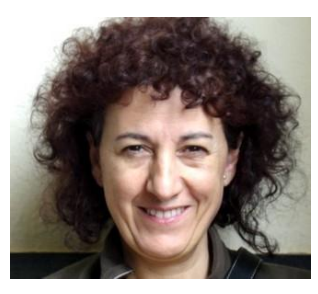

Multimodal Architecture and Interfaces https://www.w3.org/TR/mmi-arch/ (Consulted

\section{Teresa Magal-Royo}

$\mathrm{PhD}$ in Fine Arts. Universidad Politécnica de Valencia, UPV since 1997. Associate Professor at the Graphic Engineering Department. Degree: Product Design Universitat Politécnica de Valencia, Spain. Post graduate Computing in Royal College of Art, London, England.

Developing and coordinating projects related to the use of new technology in the field of education/Design and development of user-oriented interfaces/ Adaptation of graphic interfaces for viewing on mobile devices/ usability and accessibility in digital communication devices and in product design for business. Developing and coordinating new technology methods for digital communication in product design and education/Multimodal interfaces user oriented for ubiquitous devices.

She has participated in various national and international research projects on the use of technology in education. She is currently develop a research project at the London Knowledge Lab, Culture, Communication and Media Department) University College London.

Mail: tmagal@degi.upv.es

Researcher ID: K-6728-2014

ORCID: http://orcid.org/0000-0002-7640-6264

\section{Jesus García-Laborda}

$\mathrm{PhD}$ in English philology, Uinversidad Complutense de Madrid, UCM, 2000, DC Doctor of Education (Teaching of Language and Literature). European

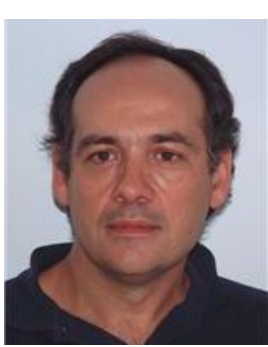
mention. UCM. 2010. Master's in ESL - U. of Georgia, 1992. Master's in Language and Comparative Literature - U. Wisconsin. Currently works as head of University in the Modern Philology Department of the University of Alcala de Henares. He teaches in grades in English Studies and Modern Languages and Translation.

The research on which works are related to applied linguistics in the field of second language learning computer-assisted.

$\mathrm{He}$ has participated in various national and international research projects on the use of technology in education in learning second languages.

Mail: jesus.garcialaborda@uah.es

Researcher ID: E-1797-2012

ORCID: http://orcid.org/0000-0003-0125-4611 